\title{
Financing Constraints, Risk of Stock Price Crash and Impact of New Crown Pneumonia
}

\author{
Jianing $\mathrm{Xu}{ }^{1,}{ }^{*}$, Rongxing Ouyang ${ }^{2}$, Nanjie Chen ${ }^{1}$, Xinyan Wan ${ }^{1}$ \\ 1. School of International Trade, Jiangxi University of Finance and Economics, Nanchang, China \\ 2. School of Accountant, Jiangxi University of finance and economics, Nanchang, China \\ *1264526211@qq.com
}

\begin{abstract}
Taking Shanghai and Shenzhen A stock listed companies as a sample, this paper uses the event research method to test the effect of financing constraints and stock price crash risk on the cumulative excess return (CAR) of enterprises under the impact of the epidemic situation. The results show that the risk of stock price collapse plays a negative role in the transmission channel of the impact of the new crown epidemic on the enterprise's cumulative excess return, and the financing constraint intensifies the negative effect. Further, the heterogeneity analysis based on firm size and ownership found that in SMEs and non-state-owned enterprises, the effect of increased financing constraints is more significant Is significant. Finally, this paper puts forward some suggestions from the perspective of relevant regulatory departments and enterprises themselves.
\end{abstract}

Keywords: CAR Financing Constrains; Stock Price Crash Risk; New Crown.

\section{Introduction}

The risk of stock price collapse is an eternal topic in the capital market, and people's attention to the risk of stock price collapse has a long history, whether in theoretical research or in practice. previous studies, stock price collapse as an important economic consequence of financial markets has been extensively explored. existing studies are mainly discussed from management characteristics [1] (li xiaorong ,2012), equity structure [2] (wang huacheng ,2015), accounting information quality [3] (Kim et al.,2014), tax avoidance [4] (jiang xuanyu ,2013). (Novel coronavirus pneumonia is the representative of the new crown pneumonia epidemic in 2019. The English name is "COVID-19". The virus causing this disease is named "sars-cov-2", and we only refer to "coronavirus" in this paper.).

Because China is in the period of economic transition at present, the financing difficulty of enterprises has always been an important problem facing our country. Whether enterprises can obtain enough funds determines the survival and healthy development of enterprises. How to solve the external financing dilemma is a topic of common concern and related practitioners. In the face of the impact of the epidemic, the financing difficulties of enterprises are more prominent, and some of the reasons for the central bank to reduce the release of liquidity are to alleviate the plight of enterprise financing.

In the market economy environment, financing constraint will increase the operating risk faced by enterprises, which is called "financing constraint risk "(Whited \&Wu,2006). Ball and Browns (1968) also believe that the information of financing constraints disclosed by listed companies will be transmitted to investors. because of the information asymmetry, external investors will take the announcement of financing constraints made by business operators as a signal for enterprises to transmit to the external market. Wang et al. (2012) [5] Demonstrates that financing constraints positively affect the idiosyncratic risk of an enterprise, corresponding to the idiosyncratic risk premium The higher. When enterprises are faced with financing constraints, due to the information transmitted to the outside world and the increase of risk premium, the stock price fluctuation of enterprises will increase, thus exacerbating the market volatility. Therefore, this paper studies the story mechanism between financing constraints, the risk of stock price collapse and the impact of the new crown pneumonia epidemic, in order to obtain useful empirical evidence. 


\section{Literature Review}

First, in the existing literature, there is not much research on the domestic epidemic situation, among which there are few studies on the impact of the epidemic situation on corporate finance. Huang Qinghua, Zhou Zhibo and others take small and medium-sized enterprises as an example to study that small and medium-sized enterprises at the low end of the value chain and the end of the industrial chain are seriously affected by the epidemic situation, generally lack of production orders, facing the risk of capital chain breakage, and difficult to resume production. Li Minglong on the Northeast small and medium-sized enterprises research, found that small and medium-sized enterprises operating income decline, operating costs increased significantly.

Financing constraints have been a hot topic in the field of corporate finance, many scholars have carried out a certain degree of research. Because of the incompleteness of capital market, such as information asymmetry, agency problem, transaction cost and so on, enterprises have financing constraints. Some scholars believe that the financing constraints of enterprises come from external factors. Fazzari \&Athey(1987)[6] research shows that the market imperfection caused by information asymmetry makes enterprises have financing constraints. A study [7] Wei Zhihua et al. (2014) shows that good financial ecological environment is better than High level of financial development and other external factors ease the financing constraints faced by enterprises. Hadlock \&Pierce (2010) [8] proposed to describe the degree of financing constraints of enterprises with internal characteristic indicators such as enterprise age and enterprise size. In addition, Ye Kangtao et al .(2010)[9] believe that reputable enterprises are often more widely recognized in the market, which reduces the financing constraints faced by enterprises by alleviating the degree of information asymmetry between enterprises and banks. Gu Lei Lei et al .(2018)[10] conducted an empirical analysis based on the structural equation model. The results show that the enterprise's own conditions have a stronger impact on financing constraints relative to the external environment. The existence of financing constraints will have an impact on the company's stock price, enterprise innovation and the enterprises. Dhawan(2001)[11] taking the listed companies in the United States as a sample for empirical research, it is found that small companies face stronger financing constraints, and then bear higher risks, thus generating stronger innovation momentum.Li(2011)[12] have a further explanation. He found that financing constraints increase the innovation risk of enterprises, so investors demand higher investors demand higher return on the return of the enterprise stock, and there is a significant positive correlation between the financing constraint and the expected return of the stock. Whited et al .(1992)[13] through empirical research, it is also found that there is a positive relationship between financing constraints and corporate stock returns. Wu Jia et al .(2014)[14] establish the dynamic enterprise investment decision model to construct the financing constraint index, and find that the stock risk and income corresponding to the high financing constraint enterprise are higher. Wang Jining et al. (2010) [15] using Barclay model analysis, it is concluded that the financial risk of financing constrained enterprises is higher than that of unconstrained enterprises.

From the collation of relevant literature on financing constraints, it can be seen that the existing literature mainly studies the reasons for the formation of financing constraints and their impact on listed companies, such as on enterprise innovation (Dhawan,2001) [11], stock return (Li, 2011; Whited,1992) [12] [13], enterprise risk (wu jia ,2014; wang jining ,2010) [14], and has not directly studied its investment behavior to enterprises and then ultimately affect the enterprise stock price volatility.

From previous studies, stock price collapse as an important economic consequence of financial markets has been extensively explored. existing studies mainly discuss from the aspects of management characteristic [1] (li xiaorong ,2012), equity structure [2] (wang huacheng ,2015), accounting information quality [3] (Kim et al.,2014), tax avoidance [4] (jiang xuanyu ,2013), etc. The marginal contribution of this paper is:First, the event research method is used to test the response of price change or price change to disclosure information by comparing the change of stock price and the change of return rate before and after the event window. Second, the existing literature mainly 
studies the causes of financing constraints and the impact on listed companies, this paper further enriched the relevant research from the risk of stock price collapse.

\section{Theory and Assumptions}

Ball and Browns [3] studies show that accounting surplus or other accounting information has explanatory and predictive value for stock prices or other economic variables. if the accounting information can cause the possible distribution of random variables of concern to the receiver and cause it to act, it can be considered that the announcement of the information sends a new signal to the market and the stock price will change. Therefore, we can observe the change of stock price to verify the usefulness of published accounting information. The hypothesis of this paper is to explore the actual rate of return after the outbreak and the theoretical rate of return estimated by the model used to assume that the epidemic did not occur, according to the difference between the cumulative excess return of enterprises, The following assumptions are therefore made:

H1: negative impact of the risk of stock price crash on the cumulative excess return

$\mathrm{H} 2$ : financing constraints aggravate the negative impact of the risk of stock price collapse on the cumulative excess return of the enterprise

H3: small and medium-sized enterprises: financing constraints significantly exacerbated the negative impact of the risk of stock price collapse on the cumulative excess return of enterprises.

H4: of non-state-owned enterprises: financing constraints significantly exacerbate the negative impact of the risk of stock price collapse on the cumulative excess return of enterprises.

\section{Models, Tape Measures and Data}

\subsection{Testing Models}

For testing hypotheses, the following OLS models are established:

$$
\begin{gathered}
C A R_{i}=\beta_{0}+\beta_{1} N C S K E W_{\mathrm{i}}+\beta_{2} D A R_{\mathrm{i}}+\beta_{3} F A R_{\mathrm{i}}+\beta_{4} R O A_{\mathrm{i}}+\beta_{5} L_{\text {nnsize }}+\beta_{6} \text { Lnage }_{\mathrm{i}}+\mathrm{u}_{\mathrm{i}} \\
C A R_{i}=\beta_{0}+\beta_{1} N C S K E W_{\mathrm{i}}+\beta_{2} N C S K E W_{\mathrm{i}} * \mathrm{WW}_{i}+\beta_{3} D A R_{\mathrm{i}}+\beta_{4} F A R_{\mathrm{i}}+\beta_{5} R O A_{\mathrm{i}}+\beta_{6} \text { Lnsize }_{\mathrm{i}}+\beta_{7} \text { Lnage }_{\mathrm{i}}+\mathrm{u}_{\mathrm{i}} \\
\text { Of which, } C A R_{i}
\end{gathered}
$$

We use the event research method to test the response of the financial stock market to the new crown epidemic. The principle is to select the research events according to the purpose of the study, and to quantitatively analyze the influence of the occurrence of the event on the change of the stock price and the rate of return of the sample, which is mainly used to test the degree of reaction of the price change or the price change to the disclosure information before and after the event occurs.

The basic assumption of the research method is that the market is rational, that is, investors will respond rationally to new information. In the actual return of the stock, it is proposed that the abnormal return can be obtained by assuming that the event does not occur and the estimated normal size of the abnormal return can reflect the degree of reaction of the stock price to the occurrence of the event. Cumulative abnormal rate of return (Cumulative Abnormal Return,CAR) method is applicable to short-term economic effect analysis, so this paper uses risk adjustment income method to calculate cumulative abnormal income.

Specifically, we first selected the event day. January 23,2020, Wuhan new coronavirus infection pneumonia epidemic prevention and control headquarters issued a circular (No .1) announced since January 23,2020 10:00, Wuhan City (hereinafter referred to as "Wuhan City Feng "). Because Wuhan Fengcheng event is not expected in theory and is only a sensitive signal in the early stage of epidemic spread.The incident gave market participants a clear message about the severity of the outbreak and the continued spread of the surrounding provinces. Therefore, this paper selects our government to declare Wuhan Fengcheng as the effective event node, and selects the corresponding January 23,2020 
as the event day.There is no uniform standard for the selection of event window period in short-term event research. The more common practice is to use 7 trading days $(-3,3)$ (Kanas,2005) [26] and 11 trading days (-5,5) (Miyajima\&Yafeh,2007) [27] before and after the event date. And it's worth noting that the stock market has been suspended for 10 days after the closing of the city (January 23) because of the New Year holiday in China, in order to avoid the result of event analysis being disturbed by other events during the Spring Festival holiday (Ding et al,) 2020) [28], this paper selects the event window with a delay period of two days, which is $(-1,0)$.

The estimated window period of this paper is 180 days, and then the normal rate of return is calculated by using the data of the estimated window $(-190,-11)$. The basic idea is to take the daily rate of return of the Shanghai and Shenzhen 300 index as the market rate of return, and to analyze the return the stock in the estimation window. Then the normal rate of return of the company per day in the event window is obtained by forecasting.

By subtracting the normal rate of return from the daily stock return in the event window $[-1,0]$, the abnormal rate of return can be obtained (Abnormal Return,AR):

$$
A R_{i, t}=R_{i, t}-E\left(R_{i, t} \mid X_{t}\right)
$$

where $R_{i, t}$ is the real rate of return of the $\mathrm{i}$ stock on the $\mathrm{t}$ day, and, $E\left(R_{i, t} \mid X_{t}\right)$ indicates the normal rate of return.

From the abnormal rate of return of all stocks, the average abnormal rate of return on the $t$ day in the event window can be obtained:

$$
A A R_{t}=\frac{\sum_{i=1}^{n} A R_{i}}{n}
$$

where $\mathrm{n}$ is the number of sample stocks. Finally, the cumulative abnormal rate of return (Cumulative Abnormal Return, CAR) and the cumulative average abnormal rate of return are calculated.

$$
\operatorname{CAR}_{t}\left(t_{1}, t_{2}\right)=\sum_{t=t_{1}}^{t_{2}} A R_{i, t}
$$

At the same time, we use the market model to calculate the abnormal rate of return (Cumulative Abnormal Return,CAR) in order to obtain a more robust conclusion.

\subsection{Definition of Variables}

1. Dependent variable

Cumulative abnormal rate of return (Cumulative Abnormal Return,CAR)

This study is based on the daily closing price data of listed companies in the latest year 2018-2019 in cathay CSAMR database (stock market series-stock market transactions).

2. Main explanatory variables

(1) Risk of individual stock crash

Based on the research of Wang Huacheng et al, this paper adopts negative return skewness coefficient NSCKEW as the measure of stock price collapse risk of listed companies. The calculation is as follows:

Firstly, in order to peel off the influence of market return on individual stock return, the weekly return rate (Ret) of i company is regressed annually by equation (1), and the weekly characteristic return rate of the company is obtained:

$$
\operatorname{Ret}_{i, t}=\alpha_{i}+\beta_{1} \operatorname{Ret}_{m, t-2}+\beta_{2} \operatorname{Ret}_{m, t-1}+\beta_{3} \operatorname{Ret}_{m, t}+\beta_{4} \operatorname{Ret}_{m, t+1}+\beta_{5} \operatorname{Ret}_{m, t+2}+\varepsilon_{i, t}
$$


Of which, $\operatorname{Ret}_{i, t}$ is the rate of return $\mathrm{i}$ the company in week $\mathrm{t}, \operatorname{Ret}_{m, t}$ is the $\mathrm{t}$ week market average yield. To control the influence of non-synchronous stock trading, we further add the leading t 1,t 2 and lag t-1,t-2. of market return. $\varepsilon_{i, t}$ is the equation residual, for the stock return can not explain the market return, that is, the idiosyncratic rate of return. i firm's idiosyncratic rate of return over the $\mathrm{t}$ week is defined as the proxy variable that $W_{i, t}=\ln \left(1+\varepsilon_{i, t}\right)$, use $W_{i, t}$ to calculate stock price crashes.

Negative return skewness coefficient (NCSKEW), mainly by measuring the negative degree of return on individual shares. The greater the negative bias, the greater the volatility of yields, the greater the risk of a crash. The $\mathrm{n}$ represents i number of trading weeks of a company's stock in one year, calculated by (2):

$$
\operatorname{NCSKE} W_{i, t}=\frac{n(n-1)^{\frac{3}{2}} \sum W_{i, t}^{3}}{(n-1)(n-2)\left(\sum W_{i, t}^{2}\right)^{\frac{3}{2}}}
$$

(2) Financing constraints

The explanatory variables in the model are the degree of financing constraints of the enterprise. Enterprises are subject to financing constraints (Fincon), most of the existing literature is based on the enterprise financial statements to construct various indicators, and then to identify whether the enterprise is subject to financing constraints and the degree of financing constraints. However, the relationship between enterprise behavior or financial characteristic variables and financing constraints is not stable or one-to-one correspondence, which makes the problem of financing constraint measurement always a controversial field in the literature. The methods of financing constraint measure mainly include: investment-cash flow sensitivity index proposed by Fazzari et al .(1987)[23]; KZ index based on comprehensive weighting of financial indicators designed by Kaplan et al .(1997)[24]; financing constraint WW index obtained by Whited and Wu(2006) with dynamic model structure; and SA index obtained by weighting some corporate characteristic indicators (Livdan et al .,2009; Hadlock \&Pierce,2010)[25]. As a result, the use of the investmentcash flow sensitivity method is prone to errors, 2007) [26], KZ indices tend to confuse financing constraints with financial dilemmas, Therefore, this paper draws on Whited and $\mathrm{Wu}$, as well as Hadlock and Pierce research, Adopt the WW index as the benchmark index to measure the degree of relative financing constraints of enterprises, SA index is used to test robustness. The WW index is specifically Whited and $\mathrm{Wu}$ [3] to calculate the Euler equation through the generalized moment estimation method to obtain the six explanatory factors of financing constraints, which are the level of long-term liabilities TLTD ( long-term liabilities/total assets), the cash flow ratio CF( net cash flow/total assets of operating activities $* 100 \%$ ), the virtual variable of cash dividend payment DIVPOS( the value of listed companies paying cash dividends is 1 , On the contrary, the value is 0 ), the natural logarithm of total assets LnTA, the growth rate of business income (SG) and the growth rate of business income (ISG) of the industry in which the enterprise is located, and then calculated according to its given coefficient The larger the value, the higher the degree of financing constraints.

3. Control variables

According to the previous research, this paper further controls the enterprise characteristic variables, as follows:

Control variable is enterprise scale (Size), expressed by logarithm of total assets of enterprise, the larger the scale of enterprise, the stronger the ability to resist risk, and the expected volatility of stock price is inversely related to it. The ratio of total liabilities to total assets is DAR, which reflects the level of liabilities, the more liabilities, the greater the, the greater the positive relationship between the expected volatility and fixed capital The ratio of production to production (FAR), expressed by the ratio of fixed assets to total assets, the expected coefficient is negative; the return on assets (ROA), expressed by the ratio of total profits to total assets. 


\section{Empirical Analysis}

A listed companies of Shanghai and Shenzhen Stock Exchange are selected in this paper. The data source is Cathay Pacific database. Through data processing (excluding companies with net assets less than 0; proposing financial companies; excluding ST companies; winsor processing at the (1/95) level; excluding samples missing from the main explanatory variables),1200 available samples were finally determined. In order to test the heterogeneity of enterprises, according to the standards of the National Bureau of Statistics, according to the scope of business income, employees and total assets of enterprises, we divide enterprises into large enterprises and small and medium-sized enterprises according to their size, and according to the nature of enterprise ownership, we divide enterprises into four sub-samples of state-owned enterprises and non-state-owned enterprises to test them separately Ownership effect and scale effect.

(1) Descriptive statistics

Table 1. Summary Statistics

\begin{tabular}{|c|c|c|c|c|c|}
\hline VarName & Obs & Mean & SD & Min & Max \\
\hline CAR & 1200 & -0.0039 & 0.040 & -0.1627 & 0.2388 \\
\hline ncskew & 1200 & -0.1924 & 0.735 & -3.3000 & 3.4519 \\
\hline nw & 1200 & -0.8143 & 16.289 & -416.5998 & 12.2682 \\
\hline dar & 1200 & 0.4135 & 0.212 & 0.0421 & 3.9191 \\
\hline size & 1200 & 22.2707 & 1.119 & 18.1093 & 26.7712 \\
\hline roa & 1200 & 0.0126 & 0.202 & -4.9465 & 0.3789 \\
\hline far & 1200 & 0.1956 & 0.138 & 0.0002 & 0.8724 \\
\hline age_ln & 1200 & 2.3680 & 0.566 & 0.6931 & 3.4012 \\
\hline
\end{tabular}

Table 1 is the descriptive statistics of the main variables in the whole sample.

(2) Relevant analysis

Table 2. Relevant analysis

\begin{tabular}{|c|c|c|c|c|c|c|c|c|}
\hline & CAR & ncskew & nw & dar & size & roa & far & age_ln \\
\hline CAR & 1 & -0.05 & -0.02 & 0.05 & $0.11^{*}$ & -0.01 & -0.02 & $0.06^{*}$ \\
\hline ncskew & -0.05 & 1 & $0.40^{*}$ & 0.01 & $0.13^{*}$ & $0.07^{*}$ & 0.06 & -0.03 \\
\hline nw & $-0.07^{*}$ & $-0.08^{*}$ & 1 & -0.02 & 0.04 & $0.10^{*}$ & 0.06 & $-0.07^{*}$ \\
\hline dar & 0.06 & 0.04 & 0.05 & 1 & $0.47^{*}$ & $-0.39^{*}$ & 0.02 & $0.26^{*}$ \\
\hline size & $0.09^{*}$ & $0.10^{*}$ & 0.06 & $0.39^{*}$ & 1 & 0.02 & -0.04 & $0.43^{*}$ \\
\hline roa & -0.03 & $-0.07^{*}$ & -0.01 & $-0.51^{*}$ & $0.12^{*}$ & 1 & 0.00 & $-0.12^{*}$ \\
\hline far & 0.02 & $0.07^{*}$ & -0.01 & 0.05 & 0.03 & -0.01 & 1 & 0.03 \\
\hline age_ln & 0.05 & -0.02 & 0.02 & $0.21^{*}$ & $0.44^{*}$ & -0.04 & $0.07^{*}$ & 1 \\
\hline
\end{tabular}

In this study, we found that the correlation coefficient between variables in regression model is less than 0.6 , so there is no multiple collinearity problem.

(3) Regression analysis

The regression results are composed of six parts according to the empirical results in Table 3 above. Column (1) only retains the regression NESKEW the negative return skewness coefficient of dependent variables and independent variables. Column (2) adds interaction terms to column (1) $\mathrm{NCSKEW}^{*} \mathrm{WW}$, and column (3)-(6) adds complete regression to control variables. The negative effects of the core variable negative return skewness coefficient NESKEW are all negative in the sixcolumn regression, as shown in Table 3, which indicates that the risk of stock price collapse has a negative effect on the cumulative excess return of the enterprise, thus confirming the hypothesis that the absolute value of the NCSKEW estimate can be observed to increase after the NCSKEW*WW of the interaction, indicating that the interaction has the effect of promoting NESKEW negative effect, indicating that the financing constraint exacerbates the negative effect of the stock price crash risk on the cumulative excess return of the enterprise, thus confirming the hypothesis H2. On the control 
variables: the asset-liability ratio of the enterprise has a significant impact DAR, SIZE enterprise scale; in column (3), only the asset-liability ratio variable is added when the core independent variable is retained, and the regression result is positive and significant. The scale of the enterprise has a significant positive effect on the cumulative excess return, which may be that the larger the scale of the enterprise, the stronger the risk ability of the enterprise to avoid the impact of the epidemic situation because of the optimization of the management level.

Table 3. Benchmark regression results

\begin{tabular}{|c|c|c|c|c|c|c|c|}
\hline Dep=CAR & $(1)$ & $(2)$ & $(3)$ & $(4)$ & $(5)$ & $(6)$ & $(7)$ \\
\hline ncskew & $-0.0029^{*}$ & $-0.0032^{* *}$ & $-0.0034^{* *}$ & $-0.0039^{* *}$ & $-0.0041^{* *}$ & $-0.0042^{* * * *}$ & $-0.0042^{* * *}$ \\
\hline & $(-1.82)$ & $(-2.03)$ & $(-2.12)$ & $(-2.42)$ & $(-2.58)$ & $(-2.60)$ & $(-2.59)$ \\
\hline nw & & $-0.0002^{* * *}$ & $-0.0002^{* * *}$ & $-0.0002^{* * *}$ & $-0.0002^{* * *}$ & $-0.0002^{* * *}$ & $-0.0002^{* * *}$ \\
\hline & & $(-2.60)$ & $(-2.72)$ & $(-2.87)$ & $(-2.89)$ & $(-2.88)$ & $(-2.88)$ \\
\hline dar & & & $0.0119^{* * *}$ & 0.0050 & -0.0023 & -0.0025 & -0.0025 \\
\hline & & & $(2.17)$ & $(0.85)$ & $(-0.31)$ & $(-0.34)$ & $(-0.34)$ \\
\hline size & & & & $0.0034^{* * *}$ & $0.0043^{* * *}$ & $0.0043^{* * *}$ & $0.0043^{* * *}$ \\
\hline & & & & $(3.04)$ & $(3.44)$ & $(3.44)$ & $(3.14)$ \\
\hline roa & & & & & -0.0119 & -0.0120 & -0.0120 \\
\hline & & & & & $(-1.63)$ & $(-1.64)$ & $(-1.63)$ \\
\hline far & & & & & & 0.0045 & 0.0045 \\
\hline & & & & & & $(0.53)$ & $(0.53)$ \\
\hline age_ln & & & & & & & -0.0000 \\
\hline & & & & & & & $(-0.01)$ \\
\hline cons & $-0.0045^{* * *}$ & $-0.0047^{* * *}$ & $-0.0097^{* * *}$ & $-0.0833^{* * *}$ & $-0.0984^{* * *}$ & $-0.0992^{* * *}$ & $-0.0993^{* * *}$ \\
\hline & $(-3.71)$ & $(-3.89)$ & $(-3.74)$ & $(-3.41)$ & $(-3.77)$ & $(-3.80)$ & $(-3.67)$ \\
\hline N & 1200 & 1200 & 1200 & 1200 & 1200 & 1200 & 1200 \\
\hline R-square & 0.0028 & 0.0083 & 0.0123 & 0.0198 & 0.0220 & 0.0222 & 0.0222 \\
\hline
\end{tabular}

$\mathrm{t}$ statistics in parentheses

$* \mathrm{p}<0.1, * * \mathrm{p}<0.05, * * * \mathrm{p}<0.01$

\section{Heterogeneity Analysis}

In order to investigate the phenomenon of enterprise ownership discrimination and scale effect, this paper tests the effect of four subsamples respectively. The regression results are shown in Table 4, column (1)-column (4):

\subsection{Heterogeneity Analysis based on Enterprise Size}

The empirical results of the above heterogeneity analysis (table), compared with two columns of large enterprises and small and medium-sized enterprises, we can find that the interaction item $\mathrm{NCSKEW}^{*} \mathrm{WW}$ has a significant negative direction in the sample data of small and medium-sized enterprises to confirm the hypothesis H3: small and medium-sized enterprises: financing constraints significantly aggravate the negative impact of the risk of stock price collapse on the cumulative excess return of enterprises. In the sample of SOEs and SMEs, the conclusion is not significant.

\subsection{Heterogeneity Analysis based on Ownership}

Confirm the assumption $\mathrm{H} 4$ : non-state-owned enterprises: financing constraints significantly aggravate the negative impact of the risk of stock price collapse on the cumulative excess return of enterprises. 
Table 4. Heterogeneity analysis

\begin{tabular}{|c|c|c|c|c|}
\hline & \multicolumn{2}{|c|}{ Scale } & \multicolumn{2}{c|}{ Ownership } \\
\hline & Large enterprises & SMEs & SOEs & Non-state enterprises \\
\hline ncskew & $-0.0048^{* * *}$ & -0.0037 & -0.0041 & $-0.0044^{* *}$ \\
\hline & $(-2.65)$ & $(-0.99)$ & $(-1.40)$ & $(-2.31)$ \\
\hline nw & -0.0000 & $-0.0003^{* * *}$ & 0.0000 & $-0.0004^{* * *}$ \\
\hline & $(-0.04)$ & $(-3.22)$ & $(0.07)$ & 0.0009 \\
\hline dar & -0.0015 & -0.0113 & -0.0067 & $(0.10)$ \\
\hline & $(-0.18)$ & $(-0.62)$ & $(-0.51)$ & $0.0035^{* *}$ \\
\hline size & $0.0059^{* * *}$ & -0.0027 & $0.0058^{* * *}$ & $(2.06)$ \\
\hline & $(3.85)$ & $(-0.62)$ & $(2.66)$ & -0.0102 \\
\hline roa & -0.0128 & -0.0035 & 0.0056 & $(-1.25)$ \\
\hline & $(-1.52)$ & $(-0.22)$ & $(0.18)$ & 0.0079 \\
\hline far & 0.0106 & -0.0263 & 0.0003 & $(0.72)$ \\
\hline & $(1.18)$ & $(-1.07)$ & $(0.02)$ & 0.0022 \\
\hline age_ln & -0.0024 & 0.0070 & -0.0066 & $(0.75)$ \\
\hline & $(-0.94)$ & $(1.28)$ & $(-1.54)$ & $-0.0894^{* * * *}$ \\
\hline cons & $-0.1334^{* * *}$ & 0.0434 & $-0.1150^{* *}$ & $(-2.61)$ \\
\hline & $(-4.32)$ & $(0.49)$ & $(-2.54)$ & 913 \\
\hline N & 1000 & 200 & 287 & 0.0287 \\
\hline R-square & 0.0264 & 0.0707 & 0.0351 & \\
\hline t statistics & pan & & & \\
\hline
\end{tabular}

$\mathrm{t}$ statistics in parentheses

$* \mathrm{p}<0.1, * * \mathrm{p}<0.05, * * * \mathrm{p}<0.01$

\section{Conclusions and Recommendations}

This paper, based on the data of listed companies of Shanghai and Shenzhen A stocks in Cathay Pacific CSAMR database, uses the event research method to observe the response degree of stock price change research to disclosure information by establishing estimation period and event window period. The risk of stock price crash plays a negative role in the transmission channel of the influence of the cumulative excess return of the enterprise, and the financing constraint intensifies. This negative effect, and in small and medium-sized enterprises and non-state-owned enterprises to aggravate the effect is more significant. Based on the findings, from the perspective of government agencies and enterprises, this paper puts forward the following suggestions on how to optimize capital market and investment decision under the impact of epidemic situation.

The perspective of government institutions: how to reduce the risk of stock price crash to promote the smooth development of the stock market can take measures to deepen the governance of tax collection and management, tax collection and management by improving corporate governance, can effectively reduce the risk of stock price falling sharply in the future; In terms of the optimization of macroeconomic policy, the state policy should strengthen monetary policy during the recession. In addition to reducing the interest rate on loans and expanding credit rationing, the banking system should improve financial and tax support for small and medium-sized enterprises and non-stateowned enterprises, enhance credit service water, strengthen the development level of venture capital market, improve the standardization of the market and release it Loose funds into the field of venture capital constraints; second, improve the transparency of the regulatory system, break monopoly and privilege rent-seeking.

For enterprises, listed companies facing financing constraints can ease the problem of insufficient investment they face when their cash flow situation is not good through the management of liquidity --cash holding, at the same time, they can standardize the management and perfect the governance institutions, and formulate strategies to deal with macroeconomic changes, thus helping to improve the efficiency of investment and the value of the company. For small and medium-sized enterprises and non-state-owned enterprises, in particular, we should improve their own development level and constantly enhance their core competitiveness: such as improving the total amount and ability of 
managers; standardizing enterprise management; perfecting the financial ability of enterprises and strengthening the role of financial leverage; and improving the ability of independent innovation.

\section{References}

[1] Li Xiaorong, Liu Xing. CEO vs CFO: gender and stock price crash risk [J]. World economy, 2012,35 (12): 102-129.

[2] Wang Huacheng, Cao Feng, ye kangtao. Supervision or tunneling: shareholding ratio of large shareholders and risk of stock price collapse [J]. Management world, 2015 (02): 45-57 + 187.

[3] Kim J B, Zhang L. Financial reporting opacity and expected crash risk: Evidence from implied volatility smirks [J]. Contemporary Accounting Research, 2014, 31(3): 851-875.

[4] Jiang Xuanyu. Tax collection and management, tax radicalization and stock price crash risk [J]. Nankai management review, 2013,16 (05): 152-160.

[5] Adrian T, Rosenberg J. Stock Returns and Volatility: Pricing the Short-run And Long-run Components of Market Risk[J]. Journal of Finance, 2008, 63(6):p.2997-3030.

[6] Ball R, Brown P. An empirical evaluation of accounting income numbers[J]. Journal of accounting research, 1968:159-178.

[7] Ma zanjun research on credit financing of small and medium sized enterprises in China, science and technology and management, 2008, (10).

[8] Wang Yang, Zheng Chunyan. Research on the impact of risk-taking of listed companies on stock price volatility [J]. Price theory and practice, 2012 (03): 57-58.

[9] Wang Huijun, Zhang Jingmin: financing constraints and Countermeasures of SMEs based on asymmetric information [J]. Journal of Chongqing University of technology and Technology (NATURAL SCIENCE), 2008, (8).

[10] Yuan Weiqiu. Financing constraints, liquidity management and corporate investment: Empirical Evidence from Shanghai and Shenzhen A-share listed companies [J]. Journal of Nanjing University of Finance and economics, 2014 (02): 38-45.

[11] Zhang Shuhui, Yuan Huan. Macro economy, financing constraints and capital structure adjustment speed [J]. Journal of Graduate School of Chinese Academy of Social Sciences, 2014 (02): 26-31.

[12] Zhou Ziyuan, Deng Yan, ye Yufu. Research on the relationship between stock price volatility and fundamental risk of Listed Companies in China [J]. Economic issues exploration, 2010 (06): 94-99. 